\title{
SITIO EL TIGRE (PDO. DE PATAGONES, PCIA. DE BUENOS AIRES, ARGENTINA): EVIDENCIAS SOBRE LA EXPLOTACIÓN DE PECES EN EL CURSO INFERIOR DEL RÍO COLORADO E IMPLICACIONES PARA LOS SISTEMAS DE SUBSISTENCIA
}

\author{
MARTÍNEZ, GUSTAVO A. ${ }^{*}$, ZANGRANDO, A. FRANCISCO ${ }^{* *}$, STOESSEL, LUCIANA ***
}

\begin{abstract}
RESUMEN
El sitio El Tigre se encuentra localizado en el área ecotonal Pampa-Patagonia, a orillas del denominado río Colorado Viejo. Como resultado del análisis de materiales de superficie y de excavaciones sistemáticas se exploraron aspectos del sitio ligados a la organización de la tecnología lítica, la subsistencia, la tecnología cerámica, la cronología $\left(\mathrm{C}^{14}\right.$-OCR $)$, los procesos de formación del sitio y su funcionalidad, entre otros aspectos. En este trabajo se resume información original referida a la subsistencia, con especial énfasis en la explotación de peces. Esta característica es, precisamente, uno de los aspectos mas destacados del sitio, ya que se trata de evidencia novedosa tanto para el curso inferior del río Colorado como para áreas y regiones aledañas. En este sentido, el sitio sugiere que los peces fluviales pudieron formar parte de la subsistencia de grupos cazadores-recolectores que habitaron la región durante el Holoceno tardío final (ca. 500 años AP). Finalmente, esta información es comparada y discutida con la procedente de áreas vecinas (Región Pampeana, Patagonia septentrional y central).
\end{abstract}

Palabras claves: Curso inferior del río Colorado - Holoceno tardío final - Explotación de peces

THE TIGRE SITE (PATAGONES DISTRICT, BUENOS AIRES PROVINCE, ARGENTINA): EVIDENCES FOR FISH EXPLOITATION IN THE LOWER BASIN OF THE COLORADO RIVER AND THEIRS IMPLICATIONS FOR SUBSISTENCE PATTERNS

\section{SUMMARY}

El Tigre site is located in the lower basin of the Colorado River. This ecotonal area between the Pampa and Patagonia regions, belong to the so-called Espinal Province, that comprises the ancient delta of the Colorado River. The site is located ca. $100 \mathrm{~m}$ from the southern coast of the Colorado Viejo River, in the sedimentary context of sand dunes. Surface collections and systematic excavations have yielded information about the organization of lithic and pottery technology, subsistence, chronology $\left({ }^{14} \mathrm{C}-\mathrm{OCR}\right)$, site formation processes as well as the function of the site.

* CONICET-INCUAPA. Departamento de Arqueología, Facultad de Ciencias Sociales, UNCPBA. Avda. del Valle 5737 (B7400JWI), Olavarría, Argentina. gmartine@soc.unicen.edu.ar

** CONICET-AIA / UBA. Rivadavia 1379 11ํF (CP1033), Ciudad Autónoma de Buenos Aires, Argentina. panchozan@yahoo. com.ar

*** Departamento de Arqueología, Facultad de Ciencias Sociales, UNCPBA. Avda. del Valle 5737 (B7400JWI), Olavarría, Argentina. stoessel@luciana.net.ar 
The main concern of this paper is to deal with aspects linked with subsistence with an emphasis in the role that freshwater fish played in hunter-gatherer diet. The most remarkable feature of the site is the abundance of fish faunal remains when comparing with other taxa. The influence of freshwater and marine fish in the studied area is discussed and a subsistence pattern for the final late Holocene (ca. 500 years BP) is proposed. Finally, comparisons in the use of fish between the lower basin of the Colorado River and neighboring regions such as Pampa and Patagonia are carried out.

Key words: Lower basin of Colorado River - Final Late Holocene - Fish exploitation

\section{INTRODUCCIÓN}

La arqueología del curso inferior del río Colorado comenzó a ser estudiada en forma sistemática a comienzos del presente milenio; hasta entonces, sólo se contó con algunos reportes aislados (Outes 1926). Estos estudios se enmarcan dentro del proyecto Investigaciones arqueológicas en el valle inferior del Río Colorado -Provincia de Buenos Aires, Argentina- (Martínez 2004), cuyo objetivo general es indagar sobre la adaptación y evolución de las sociedades cazadoras-recolectoras en el área ecotonal árida que comprende la zona de influencia del mencionado río (Fig. 1). La escasez de datos para el área hace imprescindible, como paso inicial de estas investigaciones, la construcción de un corpus de información arqueológica a los efectos de comprender aspectos de las sociedades indígenas del ámbito local, posible de ser comparado con el conocimiento generado en áreas vecinas (e.g.: sur de la región Pampeana y Norpatagonia). La subsistencia, la movilidad, la organización de la tecnología lítica, los sistemas de asentamiento, entierros humanos y análisis isotópicos, cronología radiocarbónica y por OCR, procesos de formación de sitios y estudios paleoambientales son las principales temáticas que han sido abordados hasta el momento (Armentano 2004a y b; Bayón et al. 2004; Martínez 2002, 2004; Martínez y Figuerero Torres 2000; Martínez et al. 2004a, b y c).

En esta contribución se discutirán aspectos relacionados a la subsistencia, con especial atención a la explotación de peces. Para ello se describen en forma concisa algunos aspectos de los conjuntos arqueofaunísticos del área de estudio, se presentan los resultados obtenidos del análisis ictioarqueológico efectuado en el sitio El Tigre y se examinan algunas implicaciones para la subsistencia de las poblaciones cazadoras-recolectoras del área ecotonal Pampa-Pa- tagonia y áreas vecinas. Con este estudio se busca asimismo contribuir a la discusión de problemas que exceden los límites regionales, tales como los vinculados a la variación en el aprovisionamiento de peces y su relación con aspectos de la organización espacial (e.g.: movilidad, patrones de asentamiento, etc.) de las poblaciones cazadoras-recolectoras que habitaron en Pampa y Patagonia.

\section{MARCO ECOLÓGICO DEL ÁREA DE ESTUDIO}

El curso inferior del río Colorado forma un área de ecotono fisiográfico y, posiblemente, cultural entre las regiones Pampeana y Patagónica (ver discusión en Martínez 2004; Martínez y Figuerero Torres 2000).

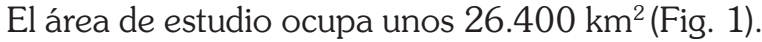
Uno de los rasgos fundamentales de este espacio lo constituye el antiguo delta del río Colorado y su evolución, reflejada en antiguos paleocauces aún detectables en el relieve y en geoformas asociadas. Estos rasgos que hoy se advierten parcialmente fueron perdiendo su fisonomía a consecuencia de la formación de geoformas fluviales, marinas y eólicas que rellenaron la depresión deltaica, generando un variado modelado geológico (Capannini y Lores 1966; Melo et al. 2004; Schäbitz 1994; Weiler 1994).Climáticamente el área está comprendida dentro de la denominada "Diagonal Árida", en la parte meridional de América del Sur (Abraham de Vázquez et al. 2000). Los estudios polínicos, geomorfológicos y pedológicos de Schäbitz (1994) en cercanías del área de estudio indican que durante el Holoceno medio y tardío los vegetales de la Zona del Espinal ya estaban presentes. Durante el Holoceno medio las condiciones climáticas habrían sido áridas, con procesos morfodinámicos eólicos predominantes, mientras que en el tardío habrían sido áridas-semiáridas, con una frecuencia mayor 
de lluvias que habrían producido la expansión de lagunas durante las fases finales del Holoceno tardío (Schäbitz 1994).

El área actualmente se caracteriza por un clima árido estepario, templado y seco, con precipitaciones que poseen una media anual de $466 \mathrm{~mm}$ y temperaturas medias anuales que van de $22,2^{\circ} \mathrm{C}$ en enero a $7,5^{\circ} \mathrm{C}$ en julio (González Uriarte et al. 1987; Sánchez et al. 1998). El tipo de vegetación dominante es el que caracteriza al Distrito del Caldén dentro de la Provincia del Espinal (Cabrera 1971), que aquí se introduce como una cuña estrecha (150 km promedio) entre las estepas de la Provincia Pampeana al norte y la Provincia del Monte al sur. Se trata de una estepa arbustiva, una formación abierta compuesta por arbustos ralos entremezclados con especies herbáceas duras y escasas. El principal componente del bosque xerófilo (caldenal) es Prosopis caldenia (caldén), especie generalmente asociada a leñosas como Prosopis flexuosa (algarrobo), Geoffroea decorticans (chañar), Jodina rhombifolia (sombra de toro), Condalia microphylla (piquillín), etc.. El área está dominada por flora de tipo $\mathrm{C}_{3}$, aunque existirían en menor medida plantas $\mathrm{C}_{4}$ (ver discusión en Paruelo et al. 1998; Villamil y Scoffield 2003).

Zoogeográficamente, el área se encuentra en la Subregión Patagónica, Distrito Patagónico (Cabrera y Yepes 1960), registrándose especies como el guanaco (Lama guanicoe), el peludo (Chaetophractus sp.), el piche (Zaedyus pichiy), la comadreja (Didelphys sp.), la liebre patagónica o mara (Dolichotis patagonum), la vizcacha (Lagostomus maximus), entre otras.

\section{ICTIOFAUNA DEL ÁREA \\ ECOTONAL PAMPA-PATAGONIA: CONDICIONES Y EXPECTATIVAS PARA EL APROVISIONAMIENTO HUMANO PREHISTÓRICO}

Desde una perspectiva biogeográfica, Patagonia se caracteriza por ser, tanto en abundancia como en diversidad, una de las regiones con mayor pobreza íctica dulceacuícola de toda Sudamérica (Ringuelet 1975). En el sector patagónico argentino están presentes quince especies de teleósteos autóctonos y diez introducidos; entre estos últimos, la familia Salmonidae es la que está mayormente distribuida en toda la región. Los peces autóctonos están comprendidos por tres especies de Siluriformes (O. viedmensis, $H$. macraei y $T$. areolatus), cuatro del género Percichthys (N.v.: perca), dos del género Galaxias (N.v.: puyén), dos del género Aplochiton (N.v.: peladilla) y una especie de pejerrey ( $P$. hatcheri). Otros peces menores y presentes en varios ambientes no cordilleranos son las madrecitas de agua (J. multidentata y C. decemmaculatus) (Ortubay et al. 1994).

Entre las especies autóctonas, las pertenecientes al género Percichthys se presentan en términos de biomasa, distribución e importancia económica como los recursos ícticos dulceacuícolas con mayor potencial para el aprovisionamiento humano prehistórico. Las percas pueden alcanzar 50 centímetros de longitud y tres kilogramos de peso (Ringuelet et al. 1967), aunque es importante mencionar que este taxón presenta una clara variación inter-específica en los tamaños. Otra característica de este recurso es su mayor accesibilidad y productividad respecto de otros taxones. Los registros efectuados por Mac Donagh (1950) en el delta del río Colorado señalan que, tanto en cursos de agua como en lagunas de escasa extensión y profundidad, puede concentrarse un gran número de percas obteniéndose pescas muy productivas de estos peces. Esto es producto de la gran resistencia respiratoria y notable adaptabilidad fisiológica a condiciones salinas que caracterizan a esta especie (Ringuelet et al. 1967). Este aspecto debe destacarse, ya que pudo haber influido en las estrategias empleadas por poblaciones cazadorasrecolectoras en la explotación de percas respecto de otras especies (e.g.: captura en masa vs. individual).

A diferencia de lo que ocurre en ambientes fluviales y lacustres de Patagonia, el espacio marino ofrece mayor diversidad y abundancia de peces. Los tipos de recursos disponibles varían a lo largo de todo el litoral patagónico, principalmente en función del tipo de costa y de condiciones de salinidad y de temperatura del agua. El entorno marino donde desemboca el delta del río Colorado se incluye biogeográficamente dentro del Conjunto Costero Bonaerense (sensu Angelescu y Prenski 1987). La lista de peces presentes en este conjunto es muy amplia, pero entre ellos dominan las corvinas rubias (Micropogonias furnieri) y pescadillas de red (Cynoscion guatucupa). Las especies cartilaginosas también son abundantes: se destacan los gatuzos 
(Mustelus shimitii), cazones (Galeorhinus galeus) y rayas (familia Rajidae) (Cousseau y Perrotta 2000). $\mathrm{Si}$ bien todos estos recursos pueden ser capturados desde la costa y algunos eventualmente ser aprovechados a partir de varamientos, un aprovisionamiento sustentable de estos peces implicaría el uso de medios tecnológicos que permitan el acceso al interior del mar, ya que allí es donde se producen las capturas más productivas (Carroza et al. 2004). Por último, dentro de este conjunto están presentes especies demersales (e.g.: merluzas [Merlucciidae sp.]), pero las probabilidades de acceso directo a dichos recursos por parte de poblaciones cazadoras-recolectoras del área considerada eran prácticamente nulas: estos peces habitan en grandes profundidades en espacios muy distantes de la costa.

En suma, existen condiciones variables para la predación humana prehistórica de peces en $\mathrm{Pa}$ tagonia Septentrional y por ende para el área de estudio. El ambiente marino tiene un mayor potencial en términos de biomasa y diversidad, conformando la fuente más rica de estos recursos, pero los peces fluviales presentan una accesibilidad y predictibilidad mayor. Tanto peces marinos como fluviales permiten efectuar aprovisionamientos en forma masiva, ya sea a partir de depositaciones naturales o mediante prácticas culturales.

\section{EL TIGRE: CARACTERÍSTICAS GENERALES Y CRONOLOGÍA DEL SITIO}

El sitio El Tigre (39 $46.826^{\prime}$ S; $62^{\circ} 22.542^{\prime}$ O) se localiza sobre unos médanos deflacionados, a 100 metros aproximadamente de la margen derecha del cauce abandonado del río Colorado Viejo y entre cinco y quince kilómetros de la costa atlántica según la distancia actual a los límites de la Bahía Anegada (Fig. 1). Los materiales superficiales se distribuyen en tres hoyadas denominadas norte, central y sur. Las hoyadas norte y central fueron relevadas superficialmente a través de transectas recolectándose gran cantidad y variabilidad de materiales arqueológicos (e.g.: desechos de talla de variadas materias primas, nódulos, núcleos, guijarros, cerámica, puntas de proyectil, restos óseos, etc.; ver Martínez 2004). Los materiales líticos superficiales

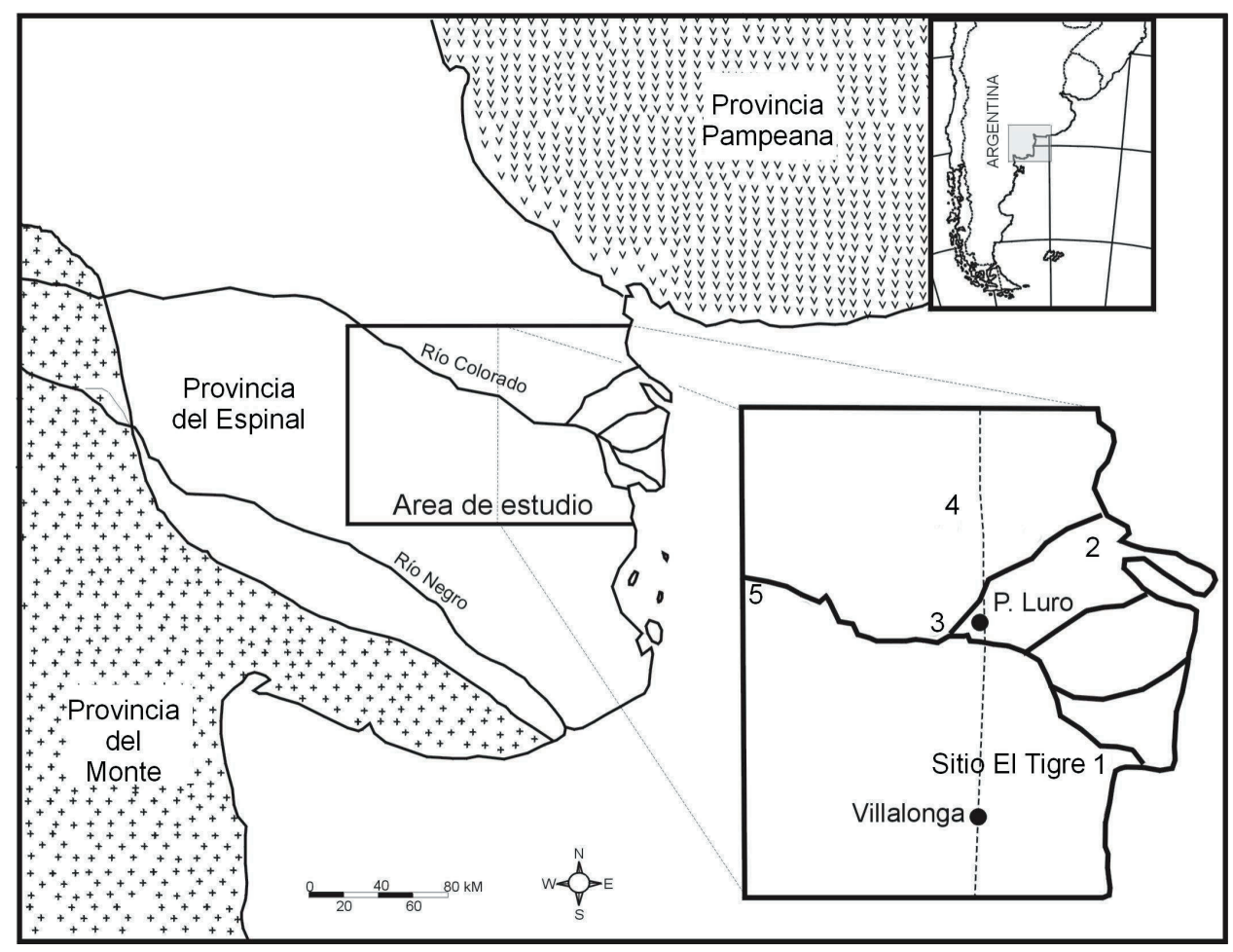

Fig. 1. Área de estudio y principales sitios arqueológicos. 1: El Tigre. 2: La Primavera. 3: La Petrona. 4: Loma Ruiz 1. 5: Paso Alsina 1 
de la hoyada central-sector norte fueron analizados por la Licenciada Gabriela Armentano (2004a). Dado que el sitio también presentaba material en posición estratigráfica, se efectuó en él una excavación de $9 \mathrm{~m}^{2}$ de extensión.

La figura 2 muestra la estratigrafía del sitio El Tigre con las principales unidades, fechas radiocarbónicas y las edades de OCR más significativas para comprender procesos de formación y los probables componentes arqueológicos del sitio. Respecto de la aplicación de la técnica de OCR en principio se muestrearon tres sectores del perfil considerando las unidades estratigráficas definidas (ver abajo), obteniéndose tres edades (Martínez 2004). Posteriormente se realizó un muestreo sistemático del perfil cada cinco $\mathrm{cm}$ obteniéndose 22 edades. Este procedimiento otorgó por un lado edades más confiables, y por otro mayores posibilidades de ajustes entre las cronologías establecidas por $\mathrm{C}^{14} \mathrm{y}$ OCR (D. Frink com. pers. 2004). De acuerdo a las

\section{Sitio: El Tigre \\ Pared este \\ Cuadrícula 9}

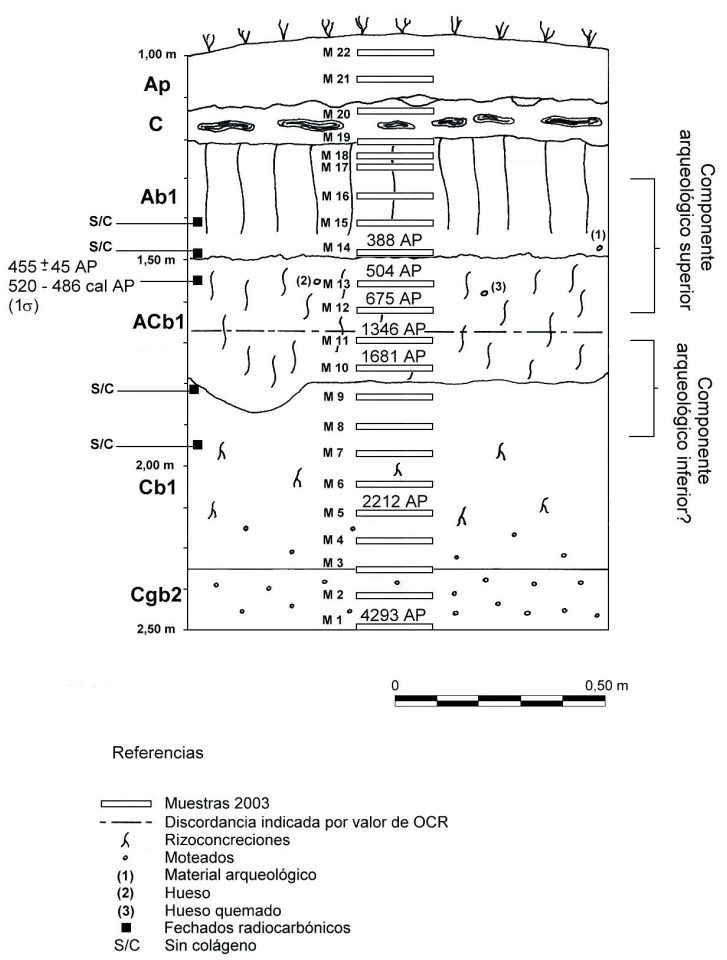

Fig. 2. Estratigrafía del sitio El Tigre primeras tres muestras analizadas (cuando aún no se contaba con fechados radiocarbónicos), y sobre la base de la ubicación estratigráfica de la mayor frecuencia artefactual (Ab1-parte superior de ACb1; ver figura 3), se estimó tentativamente la cronología del sitio grosso modo en ca. 1.970-2.040 años calendáricos AP (Favier Dubois et al. 2005; Martínez 2004: 285). Las nuevas evidencias provenientes de fechados OCR y ${ }^{14} \mathrm{C}$ que se discuten abajo rechazan esa asignación cronológica, al menos para lo que se denomina como componente superior (ver discusión abajo).

La secuencia del sitio fue estudiada por el Dr. Cristian Favier Dubois. Está compuesta, desde arriba hacia abajo, por las siguientes unidades pedoestratigráficas: Ap-C-Ab1-ACb1-Cb1-Cgb2. La unidad Ap es la unidad superior, alterada por la acción del arado. La unidad $C$ representa una unidad aluvial producto de una probable inundación por desborde de las aguas del río Colorado Viejo (ver Martínez 2004), mientras que las unidades subyacentes (Ab1, ACb1 y Cb1) son producto de eventos pedogenéticos.

Como se observa en la figura 3 , de acuerdo a las frecuencias artefactuales y al hiato temporal evidenciado por los datos OCR entre las muestras $11 \mathrm{y}$ 12 se establecieron tentativamente dos componentes arqueológicos. El superior esta más claramente definido, las frecuencias de especímenes óseos representadas por el NISP de Lama guanicoe (Fig. 3) son las más altas de todo el perfil y se encuentran en Ab1 y la parte superior de $\mathrm{ACb} 1$, comenzando a decrecer en $\mathrm{Cb} 1$ y $\mathrm{Cgb2}$. Nótese la ausencia de registro en la unidad C, correspondiente al evento de inundación.

Se enviaron para su análisis $(\mathrm{C} / \mathrm{N})$ y posterior datación cinco muestras compuestas por huesos de guanaco (Fig. 2). La muestra superior (Ab1-1,43 $\mathrm{m})$ careció de colágeno, al igual que la tomada de 1,50 m (límite entre Ab1 y ACb1). En cambio, la primera muestra procedente de ACb1 $(1,58 \mathrm{~m})$ arrojó una edad radiocarbónica de $455 \pm 45$ años AP (Ua-22561; $\left.{ }_{-}^{13} \mathrm{C}-18,6\right)$ que al ser calibrada expresa 520-486 años calendáricos AP (1_). Esta edad calibrada comprende al fechado obtenido por OCR (504 años AP, muestra 13, ver figura 2), de la misma profundidad que el espécimen datado. Otras muestras provenientes de los niveles $1,85 \mathrm{~m}$ y 1,94 m (Cb1) también carecieron de colágeno. En suma, sobre cinco muestras óseas analizadas (especimenes 
de Lama guanicoe) sólo una pudo ser datada. Las razones para la degradación del colágeno podrían deberse a $\mathrm{pH}$ alcalinos a muy alcalinos (varían entre 8,51 y 9,01), a presencia de rasgos hidromórficos (unidad C), o a oscilaciones de la napa freática que en el perfil se perciben a partir de moteados de óxidos de hierro (principalmente en unidad Cgb2); estos generaron condiciones de óxido-reducción que afectan la calidad del colágeno óseo, alterando la relación $\mathrm{C} / \mathrm{N}$ y dificultan la obtención de edades ${ }^{14} \mathrm{C}$ (Favier Dubois et al. 2005; ver discusión en Cordero et al. 1999).

El componente inferior no se expresa claramente de acuerdo a las frecuencias de especimenes óseos (Fig. 3) y su inicio se vincula a la discordancia detectada a través de los análisis de OCR (1,68 m). Por el momento, este hiato temporal se localiza en ACb1, según la clasificación morfológica de suelos, aunque en un futuro se explorará si la información provista por OCR para los niveles inferiores otorga evidencias que permitan lograr conocimiento de otros procesos actuantes. Además, estudios en curso sobre frecuencias y tamaños artefactuales, así como diferencias de materias primas líticas a través de la secuencia estratigráfica permitirán evaluar mejor la existencia de estos dos componentes arqueológicos.

En consecuencia, dada la información disponible, se considera que el componente superior se ubicaría cronológicamente en ca. 500 años AP. La evidencia material obtenida (presencia de cerámica lisa y decorada, puntas de proyectil apedunculadas triangulares pequeñas, etc.: ver Armentano 2004a y Martínez 2004) es concordante con la esperada para esa fecha y la información que se detalla más abajo sobre la subsistencia es válida para el Holoceno tardío final. Queda aún por establecer la existencia del componente inferior: si fue formado por ocupaciones distintas y diacrónicas, o si esos materiales fueron parte de los niveles superiores que, por procesos de formación del sitio, se desvincularon estratigráficamente de aquellos ubicados en niveles suprayacentes.

\section{SUBSISTENCIA}

El registro faunístico recuperado en los sitios La Primavera (ca. 2.800 años AP), Loma Ruiz 1 (ca.1.900-1.600 años AP) y El Tigre (ca. 500 años $\mathrm{AP})$ se caracteriza por la presencia de guanaco (Lama guanicoe), venado de la pampas (Ozotoceros bezoarticus), ñandú (Rhea americana) y dasipódidos (e.g.: Chaetophractus villosus) (Bayón et al. 2004; Martínez 2004; Martínez et al. 2004b y c). Los estudios de los restos óseos de los mencionados sitios se encuentran aún en proceso de análisis. Si bien se poseen cuantificaciones a nivel taxonómico y anatómico de la mayoría de las especies representadas, resta aún avanzar en aspectos tafonónicos y modificaciones de las superficies óseas (e.g.: marcas de corte). Sin embargo, análisis parciales (Martínez et al. 2004 b y c) de las especies antes mencionadas revelan la presencia en restos óseos de guanaco de superficies quemadas y fracturas intencionales. El registro arqueofaunístico de los sitios estudiados en el área muestra la explotación preferencial del guanaco $y$, secundariamente, del venado de las pampas; resta aún confirmar la explotación de especies de tamaños medianos y pequeños como Rhea, dasipódidos y roedores. Además de los recursos mencionados, la evidencia indirecta proporcionada por los materiales de molienda en diversos sitios del área (e.g.: La Petrona, ver Martínez y Figuerero Torres 2000) indicaría el consumo de vegetales probablemente vinculados a especies de la provincia del Espinal.

La excepción a este patrón de subsistencia está dada por el sitio El Tigre. Allí, además de la presencia de las especies animales mencionadas, se recuperaron evidencias del consumo de peces en una escala importante, hecho que motiva el presente trabajo. A continuación se describe en forma breve la evidencia recuperada y parcialmente analizada de los especímenes óseos sin considerar los peces (estos últimos serán tratados luego en un apartado diferente); esta información arqueofaunística proviene de las cuadrículas 1 a 9 del sitio. El conjunto está compuesto por un total de 44.830 especímenes, de los cuales 243 pudieron ser identificados en el nivel anatómico y taxonómico y 94 únicamente en el nivel anatómico; 44.403 corresponden a fragmentos indeterminados. La identificación taxonómica fue de $0,54 \%$ del total de la muestra. La ausencia de restos óseos de guanaco registrada entre los niveles de 1,06 y 1,20 m (Fig. 3, medidas tomadas desde el nivel 0) se corresponde con un hiato en el registro que coincide con la depositación de la Unidad C. Este dato es destacable debido a que la ausencia de ítems arqueológicos en esa unidad descarta la posibilidad que los elementos de los niveles inferiores hayan sido introducidos por la acción de la inundación 


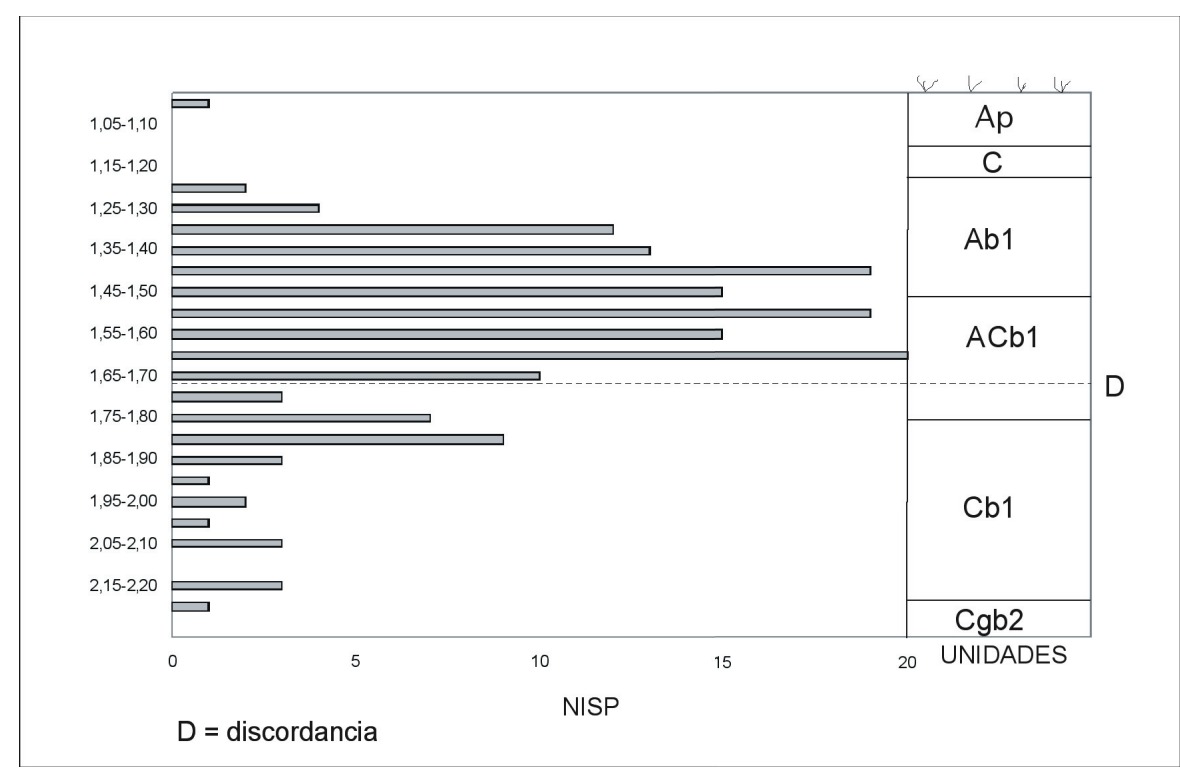

Fig. 3. NISP de Lama guanicoe. Distribución de especímenes óseos por niveles de $5 \mathrm{~cm}$

registrada. Esto cobra relevancia sobre todo en el caso de los peces, ya que la ausencia de registro en dicho depósito permite defender un origen antrópico para los especímenes recuperados en las unidades subyacentes del sitio.

Los especímenes atribuidos a guanaco constituyen más del $67 \%$ de la muestra. Los roedores están representados por el $24,2 \%$ del total de especímenes identificados, mientras que el resto de las especies no alcanzan el $5 \%$ del NISP total. El cálculo del MNI arrojó las siguientes cifras: tres guanacos, una ave, un roedor, un venado de las pampas, un ñandú y un dasipódido (cómputos parciales dan estas cifras de NISP: 52 para peludo y 16 para piche).

Es alto el grado de fragmentación del conjunto analizado, el cual se considera originado tanto por agentes naturales como culturales (un patrón distinto se observa en peces, como será discutido mas abajo). Se detectaron evidencias de explotación de las carcasas (e.g.: ca. 90 desechos de fractura helicoidal), fundamentalmente en ungulados (guanaco), así como también se advirtió la presencia de elementos con distintos grados de combustión (huesos quemados a calcinados; patrón que también se observa en el caso de los peces, ver abajo). Estratigráficamente existe una tendencia hacia mayores frecuencias de elementos óseos determinables (e.g.: guanaco, ver figura 3) entre los niveles 1,30 y $1,70 \mathrm{~m}$, correspondiente a los estratos Ab1 y parte superior de ACb1.

\section{ANÁLISIS ICTIOARQUEOLÓGICO}

Las determinaciones taxonómicas se efectuaron de la forma más específica posible. No obstante, debido a las similitudes morfológicas de los elementos óseos, estas identificaciones sólo pudieron ser realizadas en el nivel de género. Todas las determinaciones taxonómicas se efectuaron mediante el uso de colecciones óseas comparativas disponibles en el INCUAPA (FACSO-UNCPBA).

Se analizó todo el material procedente del sitio, el cual fue recuperado mediante el uso de zarandas con mallas de $3 \mathrm{~mm}$. El conjunto ictiofaunístico está compuesto por 2.100 especímenes, de los cuales el 46,4\% pudo ser identificado por taxón: 974 especímenes fueron determinados en el nivel anatómico y taxonómico, 816 sólo anatómicamente y 310 corresponden a fragmentos indeterminados.

Los especímenes atribuidos al género Percichthys sp. (percas) constituyen más del 97\% de la muestra identificada. Entre los peces fluviales menos representados se encuentran pejerreyes (P. hatcheri) y bagres pertenecientes a la familia Diplomystidae o Trichomycterinae. También están presentes dos taxones marinos: rayas (Rajidae sp.) y corvinas (Sciaena sp.). A partir del cálculo del MNI se pudo determinar la presencia de 28 percas y de un ejemplar para cada una de las restantes especies representadas (Tabla 1 ). 
Tabla 1. Abundancia ictiofaunística del sitio El Tigre

\begin{tabular}{|l|r|r|r|r|}
\hline \multicolumn{1}{|c|}{ Taxa } & NISP & \multicolumn{1}{c|}{ NISP\% } & \multicolumn{1}{c|}{ MNI } & \multicolumn{1}{c|}{ MNI\% } \\
\hline Percichthys sp. (percas) & 948 & 97,3 & 28 & 87,6 \\
Rajidae sp. (rayas) & 18 & 1,9 & 1 & 3,1 \\
Austromenidia sp. (pejerreyes) & 3 & 0,3 & 1 & 3,1 \\
Sciaenidae sp. (corvinas) & 1 & 0,1 & 1 & 3,1 \\
Siluriformes (bagres) & 4 & 0,4 & 1 & 3,1 \\
\hline Total & 974 & 100 & 32 & 100 \\
\hline
\end{tabular}

Con relación a las partes anatómicas, los especímenes correspondientes a Percichthys $s p$. comprenden tanto huesos del cráneo como del esqueleto axial; la representación de ambas partes se mantiene en toda la secuencia estratigráfica (Fig. 4). Las vértebras precaudales conforman la unidad anatómica con mayor abundancia relativa, prevaleciendo ampliamente sobre las vértebras caudales. El basioccipital es el elemento más representado del neurocráneo. También están presentes, aunque en menor proporción, otros huesos del cráneo, entre los que se destacan los pertenecientes al segmento maxilofacial: cuadrado, dentario y premaxilar (Tabla $2)$. Respecto de las restantes especies, las rayas se encuentran representadas por 18 huesos dérmicos, corvinas y pejerreyes por una y tres vértebras respectivamente, y el ejemplar de siluriforme por un supraoccipital.

Las observaciones etnoarqueológicas efectuadas por Stewart y Gifford-Gonzalez (1994) sobre perciformes señalaron que la representación de partes anatómicas registrada en conjuntos culturales difiere marcadamente de la observada en depósitos naturales; en estos últimos la proporción de unidades craneales alcanza un $70 \%$ del total de la muestra. Este patrón difiere claramente del observado en El Tigre, donde prevalecen vértebras (88\%) sobre huesos del cráneo (12\%); lo cual evidencia un origen antrópico del conjunto estudiado. Coincide también con lo señalado por Butler (1996; ver también Lyman 1994) respecto de los depósitos culturales, los cuales estarían conformados por carcasas incompletas y donde los elementos axiales estarían mucho más representados que los correspondientes al cráneo. Asimismo, la presencia de restos óseos con distintos grados de combustión (entre quemados y calcinados) refuerzan este argumento.

Recientes trabajos tafonómicos en restos de peces se han focalizado sobre la densidad ósea, el tamaño y la forma de los elementos como factores críticos para la conservación de partes anatómicas (Butler y Chatters 1994; Falabella et al. 1994; Lubinski 1996; Musali 2005; Nicholson 1992). Lamentablemente, no disponemos de valores

Tabla 2. Medidas de abundancia anatómica de Percichthys sp.

\begin{tabular}{|c|c|c|c|c|c|}
\hline & & s anatómicas & MNE & MAU & MAU\% \\
\hline \multirow{14}{*}{ CRÁNEO } & \multirow{10}{*}{ 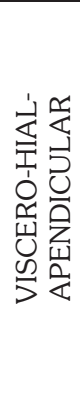 } & Articular & 4 & 2,0 & 6,4 \\
\hline & & Ceratohial & 9 & 4,5 & 14,4 \\
\hline & & Cleitro & 3 & 1,5 & 4,8 \\
\hline & & Cuadrado & 17 & 8,5 & 27,2 \\
\hline & & Dentario & 10 & 5,0 & 16,0 \\
\hline & & Epihial & 5 & 2,5 & 8,0 \\
\hline & & Hiomandibular & 3 & 1,5 & 4,8 \\
\hline & & Interopercular & 4 & 2,0 & 6,4 \\
\hline & & Palatino & 3 & 1,5 & 4,8 \\
\hline & & Premaxilar & 8 & 4,0 & 12,8 \\
\hline & \multirow{4}{*}{$\begin{array}{l}\text { O } \\
\text { 号 } \\
\text { 㞱 }\end{array}$} & Basioccipital & 28 & 28,0 & 89,7 \\
\hline & & Otolito & 2 & 1,0 & 3,2 \\
\hline & & Postemporal & 3 & 1,5 & 4,8 \\
\hline & & Vómer & 6 & 6,0 & 19.2 \\
\hline \multirow{2}{*}{\multicolumn{2}{|c|}{ AXIAL }} & Vértebra caudal & 329 & 17,3 & 55,4 \\
\hline & & Vértebra precaudal & 469 & 31,2 & 100,0 \\
\hline
\end{tabular}


específicos de estas variables para Percichthys sp.. No obstante, consideramos que los estudios efectuados por Falabella et al. (1994) y Musali (2005) proveen un marco de referencia adecuado para efectuar una exploración de estos aspectos. En este sentido, la alta representación de vértebras, aunque registren bajas densidades óseas en comparación con los elementos del cráneo (Musali 2005), estaría favorecida por elevados índices morfológicos y por la alta frecuencia que presentan estas unidades por individuo. Sin embargo, elementos craneales con bajos índices morfológicos y de densidades óseas están altamente representadas en el conjunto analizado; la mayor parte de estos huesos corresponden al segmento maxilofacial. La relación inversa existente entre estos parámetros y la representación de elementos óseos señalaría virtualmente que los procesos de modificación ósea postdepositacional no jugaron un papel significativo en la formación de este conjunto. Por otro lado, el grado de fragmentación establecido fue de 1,17, lo cual también señala una buena integridad del registro ictiofaunístico.

\section{DISCUSIÓN}

La información discutida previamente señala que la explotación de peces se focalizó en espacios fluviales. Este factor es importante, ya que constituye el primer registro para la zona de transición ecotonal Pampa-Patagonia sobre un aprovisionamiento humano prehistórico de estos recursos dulceacuícolas. Si bien en términos de biomasa y diversidad el ambiente marino constituye la fuente más rica de estos recursos, las condiciones de accesibilidad que caracterizan a los peces fluviales parecen haber sido más favorables. Sin embargo, es necesario considerar que los peces marinos presentes en el registro arqueológico están mayormente representados por especies de la familia Rajidae, cuya importancia económica es difícil de estimar debido a que sus esqueletos están compuestos principalmente por cartílagos, los cuales en raras ocasiones se conservan. Asimismo, mientras que son numerosos los elementos de teleósteos que pueden ser identificados, en los peces cartilaginosos las unidades óseas diagnósticas son muy escasas. De esta manera, la estimación de la abundancia relativa basada sólo sobre el uso de frecuencias absolutas puede llevar a una interpretación sesgada en cuanto a la importancia económica de un tipo de recurso íctico respecto de otro (Rick y Erlandson 2002). Al considerar esto, se abre la posibilidad de que la contribución de peces marinos a la subsistencia de las poblaciones cazadoras-recolectoras que habitaron la región haya sido mayor de la que se percibe a partir del conjunto ictiofaunístico. No obstante, si analizamos este aspecto a la luz de otras evidencias paleodietarias, observamos que la incidencia de estos recursos marinos en la dieta también fue baja: los análisis isotópicos realizados sobre esqueletos humanos provenientes de los sitios La Petrona, La Primavera, Don Aldo 1 y Paso Alsina 1 sugieren que para el lapso ca. 3.000-300 años AP la dieta habría sido básicamente continental (terrestre),

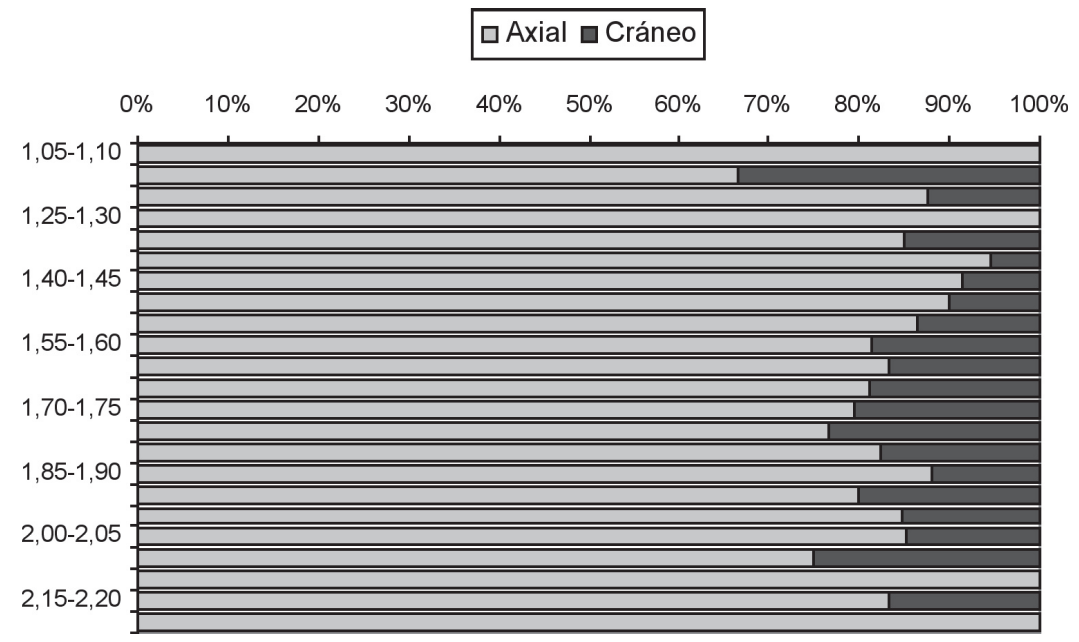

Fig. 4. Distribución en estratigrafía de partes anatómicas de Percichthys sp. 
reflejando la ingesta predominante de herbívoros consumidores de plantas $\mathrm{C}_{3}$ y un posible consumo directo de estos vegetales (Martínez 2002, 2004; Martínez y Zangrando 2004).

Otra vía de discusión consiste en explorar las estrategias vinculadas a la adquisición y el consumo de recursos ícticos. La mayor representación de percas en el conjunto ictiofaunístico es coincidente con las expectativas propuestas a partir de la información ecológica. Sin embargo, si bien la explotación de este recurso pudo haberse dado mediante prácticas de captura en masa, en el conjunto arqueológico analizado no fue posible identificar artefactos que evidencien las técnicas empleadas en dicha actividad. Esto podría responder a dos razones: a problemas en la preservación del registro artefactual, o bien a la aplicación de técnicas o formas de aprovisionamiento que no son visibles arqueológicamente. Entre estas últimas podrían considerarse la recolección oportunista a partir de depositaciones naturales (Zangrando 2003) o el empleo de barbasco (Béarez 1998); por medio de ambos procedimientos es posible lograr abastecimientos masivos.

La falta de un registro artefactual relacionado con las actividades de pesca concuerda con lo mencionado en documentos de cronistas y viajeros. La tendencia general de los relatos remarca el desinterés de los indígenas por los peces. Viedma (1783) relata que los indígenas que habitaban en las cercanías de Puerto de San Gregorio no pescaban, desconocían los modos de captura y no poseían la tecnología para ello (Viedma 1783: 940). Musters, refiriéndose a grupos de Tehuelches del norte que se desplazaban entre los ríos Negro y Senguel, llegando esporádicamente a Carmen de Patagones, describe que él salía de pesca y obtenían presas parecidas a las percas y bagres pero que los indígenas no consumían pescado (Musters 1997: 142-143). Bórmida y Casamiquela (1958-59: 165) plantean, según datos proporcionados por un informante, que los Tehuelches septentrionales no pescaban ni comían peces de mar ni de río; según esos investigadores, el informante no mostraba desagrado por este recurso y explicaba la ausencia de su consumo por la lejanía al mar y la ausencia de aguas dulces (aspectos que no son consistentes con nuestro caso de estudio ya que ambos recursos, marinos y fluviales, están disponibles en las inmediaciones). D’Orbigny (1999) destacó las diferencias entre los patagones (refirién- dose tanto a los Tehuelches septentrionales como meridionales, pag.320) y los habitantes de Tierra del Fuego en cuanto a la carencia de los primeros de toda aptitud para la pesca. No obstante, comentó que se contentan con apoderarse de los peces que el azar pone a su alcance sin usar la red ni otro procedimiento (D’Orbigny 1999: 325). Lista (1894:100) sostuvo que los peces eran considerados inmundos. Es posible que estas observaciones se encuentren en parte sesgadas debido a los profundos cambios experimentados por los aborígenes de Norpatagonia para el siglo XVIII. Sin embargo, las razones por las cuales pueda darse un desinterés en el consumo de peces son muy diversas y pueden incluir aspectos económicos, sociales e incluso ideológicos (Politis y Martínez 1996; Politis y Saunders 2002; Ross 1978). Bajo estas circunstancias, Malainey et al. (2001) sostienen que grupos cazadores-recolectores con un énfasis dietario en carnes magras podrían quedar expuestos a los efectos de una mala absorción de lípidos por el consumo de peces. Este argumento podría ser válido para las poblaciones aborígenes que habitaron Norpatagonia.

Como mencionamos anteriormente, la escasa presencia de restos de peces en otros sitios ubicados en la cuenca inferior del río Colorado marca una discrepancia con respecto a lo observado en $\mathrm{El}$ Tigre, lo cual puede deberse a múltiples factores. Entre estos últimos, las prácticas relacionadas con el procesamiento y descarte constituyen una parte importante de los procesos que introducen variabilidad en los conjuntos arqueofaunísticos en una escala regional. En circunstancias donde existe estrecha relación espacial entre las ocupaciones humanas y las áreas potenciales para el aprovisionamiento de peces, surgen expectativas diversas sobre la formación de estos conjuntos. De acuerdo con lo propuesto por Stewart y Gifford-Gonzalez (1994), es posible distinguir tres patrones en el registro ictiofaunístico correlacionados con actividades específicas: ocupaciones residenciales, áreas de trozamiento y espacios de descarte. Las ocupaciones residenciales se caracterizan por una baja diversidad taxonómica y una alta representación de distintas partes anatómicas del esqueleto (principalmente vértebras); se exceptúan los casos de procesamiento para consumo diferido, en los que se espera una baja representación del esqueleto axial (Hoffman et al. 2000; Stewart y Gifford-Gonzalez 1994). Las áreas de trozamiento 
muestran, en cambio, una alta diversidad taxonómica y los huesos del cráneo prevalecen en forma significativa sobre las vértebras. Por último, en los espacios de descarte están representadas mayormente espinas dorsales, las cuales son removidas y desechadas en momentos inmediatos a la captura. La composición ictiofaunística presente en El Tigre muestra una baja diversidad taxonómica y una representación variable de diferentes partes anatómicas de percas en toda la secuencia estratigráfica, aunque es notoria la mayor abundancia de elementos entre los niveles 1,35 y 1,85 m. La conformación de este conjunto óseo es coincidente con lo propuesto por Stewart y Gifford-Gonzalez (1994) para ocupaciones residenciales. Esta interpretación es coherente con la establecida en trabajos previos (Armentano 2004a; Martínez 2004) a partir de otras líneas de evidencias arqueológicas tales como variabilidad de tipos de desechos de talla de diversas materias primas, representación de cadenas operativas según materias primas de diferentes grados de desarrollo y complejidad técnica, variabilidad artefactual con predominancia de puntas de proyectil triangulares pequeñas, presencia de abundante cerámica con restos de hollín y adherencias internas, diversidad faunística, etc.

Desde una perspectiva espacial más amplia, uno de los problemas que deberá ser abordado en el futuro apunta a establecer en qué medida las variaciones en la explotación de peces pudieron relacionarse con aspectos de la organización espacial de las sociedades cazadores-recolectores que habitaron en Pampa y Patagonia. Una exploración inicial señala que existió variabilidad en relación a estos aspectos. A excepción de las áreas norte (Acosta 2005; Acosta y Musali 2002; Brunazzo 1999; Musali 2005; Paleo et al. 2002) y de la depresión del Salado (González de Bonaveri 2002; González de Bonaveri et al. 1999; González de Bonaveri et al. 2003), donde los peces tuvieron una incidencia significativa en la subsistencia de las poblaciones cazadoras-recolectoras, en el resto de las áreas que componen la región Pampeana los peces no formaron parte de la subsistencia (Martínez y Gutiérrez 2004; Politis y Salemme 1990). A modo de generalización, cabe destacar que en esta región el aprovisionamiento de peces se efectuó primordialmente en ambientes fluviales, siendo muy escasos los registros que sustentan una explotación marina de estos recursos (ver discusión en Cione y Bonomo 2003).

En el caso de Patagonia septentrional, región en la cual se incluye parte del área de estudio del presente trabajo, son escasos los antecedentes que señalan la presencia de peces en el registro arqueológico y los hallazgos efectuados hasta el momento han sido menos numerosos que el observado en El Tigre. Entre los registros más significativos se encuentra el sitio El Trébol, ubicado en San Carlos de Bariloche, con un total de 127 especímenes de peces distribuidos a lo largo de toda la secuencia estratigráfica (Hajduk et al. 2004); el MNI establecido fue de siete ejemplares, cada uno de ellos ubicados en niveles estratigráficos distintos. Los taxones identificados corresponden a Percitchys trucha y otras dos especies, probablemente pejerrey y bagre (Hajduk et al. 2004). En el alero Los Cipreses, margen norte del río Traful, la evidencia ictiofaunística es muy escasa, no obstante se destaca la presencia de un anzuelo (Silveira 1996). Los registros disponibles para la cuenca del río Limay también señalan frecuencias muy bajas de restos óseos de peces (Fernández y Crivelli Montero 2004; Menegaz 1996): en el sitio Piedra del Águila 11 el material ictiofaunístico muestra indicios de combustión (Menegaz 1996). En el curso medio del río Colorado, Gradin y Aguerre (1984) mencionan la presencia de un esferoide posiblemente utilizado como útil de pesca en la ocupaciones medias de Casa de Piedra 1. Asimismo, en los sitios Ojo de Agua y Angostura se recuperaron restos de peces termoalterados en posible asociación con el registro arqueológico (Prates 2004). Recientes investigaciones efectuadas en la costa rionegrense han documentado la presencia de otolitos y huesos de peces marinos (Borella et al. 2004). En resumidas palabras, la información disponible para Patagonia septentrional señala que si bien la incidencia de peces fluviales en la subsistencia de poblaciones cazadoras-recolectoras no parece haber sido tan significativa como la observada en algunos sectores de la región Pampeana, su importancia fue mayor respecto de los recursos ícticos marinos. No obstante, cabe mencionar que estos últimos están presentes en diversos de sitios de la cuenca inferior del río Colorado (Bayón et al. 2004; Martínez y Figuerero Torres 2000) y en emplazamientos costeros como el sector norte del golfo de San Matías (Borella com. pers.). 
En Patagonia central, diversos autores señalaron la presencia de peces en sitios arqueológicos ubicados a lo largo del litoral atlántico (Caviglia y Borrero 1978; Caviglia et al. 1982; Gómez Otero et al. 1998; Izeta 1999; Miotti 1993; Moreno y Castro 1995), siendo sumamente escasos los registros de estos recursos en el interior (Cassiodoro et al. 2004; Fernández 1996-97). A excepción del sitio Moreno, los especímenes óseos de peces recuperados en el registro arqueofaunístico son escasos. Los análisis realizados en el sitio Moreno señalan una predominancia de especies marinas como merluzas (Merluccius hubbsi), pejerreyes (Odontesthes sp.) toritos (Bovychtis sp.) y róbalos (Eleginops maclovinus) (Izeta 1999). En sitios de península Valdés predominan meros (Acanthistius brasilienses), seguidos por anchoas (Pomatomus saltator) y turcos (Pinguipes brasilianus) (Gómez Otero et al. 1998). El hallazgo de un anzuelo de madera en la costa norte del golfo San José sugiere que se pudieron haber efectuado capturas de peces medianos a grandes en piletones de mareas (Gómez Otero 1995, 1996). En Bahía Solano, análisis efectuados sobre vértebras indicaron que el aprovisionamiento de peces se desarrolló en verano (Caviglia et al. 1982). En suma, la tendencia observada en el sector central de Patagonia es un mayor aprovisionamiento de peces marinos, lo cual marca una discrepancia con respecto a lo observado en la región Pampeana y Norpatagónica.

\section{CONSIDERACIONES FINALES}

Por todo lo expuesto anteriormente, la presencia de peces fluviales en El Tigre es claramente de origen antrópico y el recurso fue consumido. La presencia de algunas especies de mar (e.g.: corvina y raya) había sido ya registrada con anterioridad en otros sitios del área (e.g.: La Petrona y La Primavera; Bayón et al. 2004; Martínez y Figuerero Torres 2000) pero su frecuencia es muy escasa y, en consecuencia, no puede considerarse hasta el momento como parte importante de la subsistencia en el área ecotonal Pampa-Patagonia. En suma, la evidencia arriba descrita para el sitio El Tigre señala un patrón de subsistencia caracterizado por el aprovechamiento conjunto de recursos continentales, terrestres (e.g.: guanaco, venado y vegetales) y fluviales (e.g.: peces), al menos durante la parte final del Holoceno tardío. Este patrón ha sido observado también en otras áreas de Patagonia septentrional (Gradin y Aguerre 1984; Hajduk et al. 2004).

Si bien la mención de casos etnohistóricos y actuales es escasa, es notable la disparidad de la información provista por éstos cuando se la compara con el registro arqueológico del sitio estudiado, donde los peces ocupan un rol central (al menos en lo que respecta a la información cuantitativa). En este sentido, y por dar un ejemplo, mientras que el MNI de percas asciende a 28, los guanacos están representados por un $\mathrm{MNI}=3$ y el resto de las especies por un $\mathrm{MNI}=1$. Por supuesto que las potencialidades alimenticias de cada una de estas especies, de sus rindes económicos y su vinculación a las estrategias económicas del área como un todo son muy diferentes, pero la disparidad en la cuantificación de los recursos sin duda otorga un rol a los peces fluviales que debe ser indagado. En tanto el aprovisionamiento de guanaco es interpretado como una actividad recurrente y pautada, se desconoce si estas pescas, posiblemente masivas, habrían sido actividades frecuentes o coyunturales y contingentes. En cualquier caso, la lectura inmediata que puede hacerse de la estructura faunística del sitio El Tigre es, por un lado, la advertencia de que la pesca fluvial ha jugando un rol importante durante el Holoceno tardío final y, por otro, que este caso aumenta la variabilidad de sitios reconocida para el período. En este sentido, además de sitios de actividades múltiples donde se realizaron inhumaciones primarias y secundarias (e.g.: La Petrona; Martínez y Figurero Torres 2000), de sitios de actividades múltiples donde se llevaron a cabo inhumaciones primarias (Don Aldo 1; Prates et al. 2005), de áreas formales compuestas por entierros secundarios (Paso Alsina 1; Martínez et al. 2004a), se agrega el registro de bases residenciales como El Tigre.

Por último, además de la riqueza y variabilidad artefactual, el sitio El Tigre también se caracteriza por presentar una estructura del registro faunístico desconocida hasta ahora, tanto para el área de estudio como para áreas y regiones colindantes. De esta forma, el conocimiento obtenido abre nuevos interrogantes referidos a la subsistencia de las poblaciones indígenas de las áreas Pampeanas, de ecotono Pampeano-Patagónico y Patagónicas ligadas al litoral atlántico, donde el aporte de peces a la subsistencia deberá ser explorado. 


\section{AGRADECIMIENTOS}

Los autores agradecen a los Sres Raúl Ilgner, propietario de la Ea. El Tigre y a Angel Aman por la hospitalidad brindada durante los trabajos de campo. Las determinaciones iniciales de peces del sitio por parte de Dr. A. Cione resultaron de gran valor para comprender la potencialidad del sitio en cuanto a la representación de este recurso que dio, finalmente, origen a este trabajo. Al Lic. Luciano Prates por la orientación en la búsqueda de crónicas referidas al (no) consumo de peces por parte de las poblaciones indígenas. Al Dr. Cristian Favier Dubois y a Douglas Frink por sus aportes referidos a la geología, cronología y procesos de formación del sitio. A Roberto López y Cristian Kaufmann por su ayuda en la parte gráfica. Los trabajos fueron financiados por subsidios de la Wenner Gren Foundation for Anthropological Research (Grant Nro. 6780) y la Fundación Antorchas (Proyecto 14022-2) otorgados a uno de los autores (GM). Al INCUAPA (FACSOUNCPBA) por brindar la infraestructura y materiales de comparación. Por último, queremos agradecer a los Licenciados Luis Orquera y Javier Musali por los comentarios y las sugerencias realizadas sobre versiones preliminares de este trabajo.

\section{BIBLIOGRAFÍA}

ABRAHAM DE VÁZQUEZ, E., GARLEFF, K., LIEBRICHT, H., REIGARÁZ, A, SCHÄBITZ, F., SQUEO, F., STINGL, H., VEIT, H. y C. VILLAGRÁN 2000. Geomorphology and Paleoecology of the Arid Diagonal in Southern South America. Geodesy, Geomorphology and Soil Science. Sonderheft ZAG: 55-61.

ACOSTA, A. 2005. Zooarqueología de cazadores-recolectores del extremo nororiental de la provincia de Buenos Aires (humedal del río Paraná inferior) (Región Pampeana, Argentina). Tesis Doctoral Inédita, Universidad $\mathrm{Na}$ cional de La Plata, Facultad de Ciencias Naturales y Museo. MS.

ACOSTA, A. y J. MUSALI 2002. Icitioarqueología del sitio La Bellaca 2 (Pdo. de Tigre, Pcia. de Buenos Aires). Informe preliminar. Intersecciones en Antropología 3: 3-16.

ANGELESCU, V. y L. PRENSKI 1987. Ecología trófica de la merluza común del Mar Argentino (Merlucciidae, Merluccius hubbsi). Parte 2. Dinámica de la alimentación analizada sobre la base de las condiciones ambientales, la estructura y las evaluaciones de los efectivos en su área de distribución, Contribución INIDEP 561: 1-205.

ARMENTANO, G. 2004a. Organización de la Tecnología Lítica en el valle inferior del río Colorado (Partidos de Patagones y Villarino, Pcia. de Buenos Aires). Tesis de Licenciatura Inédita. FACSO-UNICEN. Olavarría. MS.
ARMENTANO, G. 2004b. Observaciones preliminares acerca de la organización tecnológica del valle inferior del río colorado: sitio Caldén Guazú -Médano 1-Sector Este. En: Aproximaciones Contemporáneas a la Arqueología Pampeana, pp. 227-246. Editado por G. Martínez, M. Gutierrez, R. Curtoni, M. Berón y P. Madrid. Publicación de la Facultad de Ciencias Sociales. UNCPBA. Olavarría.

BAYÓN, C.; MARTÍNEZ, G.; ARMENTANO, G. y C. SCABUZZO 2004. Arqueología del valle inferior del río Colorado: el sitio La Primavera. Intersecciones en Antrpología 5: 39-53.

BÉAREZ, P. 1998. FOCUS: First Archaeological Indication of Fishing by Poison in a Sea Environment bythe Engoroy Population at Salango (Manabí, Ecuador). Journal of Archaeological Science 25: 943-948.

BORELLA, F.; FAVIER DUBOIS, C.; LANZELOTTI, S. y M. CARDILLO 2004. Proyecto arqueológico en el golfo San Matías (Río Negro). Primera etapa de las investigaciones. En: Libro de Resúmenes del XV Congreso Nacional de Arqueología Argentina, p. 362. Río Cuarto.

BÓRMIDA, M. y R. CASAMIQUELA 1958-1959. Etnografía Gununa-Kena. Testimonio del último de los Tehuelches Septentrionales. Runa IX, partes 1-2: 153-193.

BRUNAZZO, G. A. 1999. Investigaciones arqueológicas en el sitio La Norma (Partido de Berisso, Provincia de Buenos Aires, Argentina).En: Actas del XII Congreso Nacional de Arqueología Argentina, Tomo 3, pp. 101-106. La Plata.

BUTLER, V. L. 1996. Tui Chub taphonomy and the importance of marsh resources in the western great basin of North America. American Antiquity 61: 699-717.

BUTLER, V. y J. CHATTERS 1994. The role of bone density in structuring prehistoric salmon bone assemblages, Journal of Archaeological Science 21: 413-424.

CABRERA, A. 1971. Fitogeografía de la república Argentina. Boletín de la Sociedad Argentina de Botánica 14: $1-42$.

CABRERA, A y J. YEPES 1960. Mamíferos Sudamericanos Tomo I. $2^{\circ}$ Edición. EDIAR. Buenos Aires.

CAPPANNINI, D. y R. LORES 1966. Los suelos del valle inferior del río Colorado. Colección Suelos, $\mathrm{N}^{\circ} 1$, INTA. Buenos Aires.

CARROZA, C.; FERNÁDEZ ARAOZ, N.; DUARTE, C.; MASSA, A.; HOZBOR N. y A. JAUREGUIZAR 2004. Definición de una zona de reproducción y cría de especies demersales costeras en la costa sur de la Provincia de Buenos Aires, Informe Técnico Interno INIDEP 84. MS.

CASSIODORO, G. ; ARAGONE A. y A. RE 2004. Más allá de los chenques... Registro arqueológico de sitios a cielo abierto en la cuenca de los lagos Salitroso y PosadasPueyrredón. En: Contra Viento y Marea. Arqueología de Patagonia, pp. 325-338. Editado por Civalero, M. T.; Fernández, P. M. y A. G. Guráieb. Buenos Aires.

CAVIGLIA, S. y L. A. BORRERO 1978. Bahía Solano. Su interpretación paleoetnozoológica en un marco regional. Trabajo presentado en el V Congreso Nacional de Arqueología Argentina, San Juan. MS

CAVIGLIA, S.; BORRERO, L. A.; CASIRAGHI, M.; GARCÍA, L. C. y V. HORWITZ 1982. Nuevos sitios arqueológicos para la región Bahía Solano (Chubut). Trabajo presentado 
en el VII Congreso Nacional de Arqueología Argentina, San Luis. MS.

CIONE, A. L. y M. BONOMO 2003. Great White Shark Teeth Used as Pendants and Possible Tools by Early-Middle Holocene Terrestrial Mammal Hunter-Gatherers in the Eastern Pampas (Southern South America). International Journal of Osteoarchaeology 13 : 222-231.

CORDERO, R.; FAVIER DUBOIS, C. y M. DO SANTOS AFONSO. 1999. Consideraciones acerca de la confiabilidad de las muestras en las dataciones por carbono catorce. El caso de los sitios San Genaro en la Bahía de San Sebastián (Norte de Tierra del Fuego). En: Actas del XII Congreso Nacional de Arqueología Argentina, Tomo II, pp. 335-348. La Plata.

COUSSEAU, M. B. y R. G. PERROTTA 2000. Peces marinos de la Argentina. Biología, distribución, pesca. INIDEP (Segunda edición). Mar del Plata.

D'ORBIGNY, A. 1999. Viaje por América Meridional II. Editorial Emecé. Buenos Aires.

FALABELLA, F.; LORETO VARGAS, M. y R. MELÉNDEZ 1994. Differential preservation and recovery of fish remains in Central Chile. Annales du Musée Royal de l'Afrique Centrale, Sciences Zoologiques 274: 25-35.

FAVIER DUBOIS, C.; G. MARTÍNEZ Y D. FRINK 2005. Estratigrafía, cronología y paleoambiente en el curso inferior del río Colorado (Pdos. De Villarino y Patagones, Pcia. de Buenos Aires). MS.

FERNÁNDEZ, P. 1996-97. Integridad y Resolución del Conjunto Arqueofaunístico de Campo Cerda 1 (Provincia del Chubut, Argentina). Cuadernos del Instituto de Antropología y Pensamiento Latinoamericano 17: 205-228.

FERNÁNDEZ, M. M. y E. A. CRIVELLI MONTERO 2004. Excavaciones de Rescate en Rincón Chico 2/87, Provincia del Neuquén. En: Contra Viento y Marea. Arqueología de Patagonia, pp. 701-714. Editado por Civalero, M. T.; Fernández, P. M. y A. G. Guráieb. Buenos Aires.

GÓMEZ OTERO, J. 1995. Bases para una arqueología de la costa patagónica central (entre golfo San Jorge y cabo Blanco). Arqueología 5: 61-103.

1996. Primera noticia sobre el hallazgo de un anzuelo de madera en Patagonia: sus implicancias en el contexto de la arqueología regional. En: Arqueología. Solo Patagonia, pp. 59-67. Editado por Gómez Otero, J.. Puerto Madryn.

GÓMEZ OTERO, J.; LANATA, J. L. y A. PRIETO 1998. Arqueología de la costa Atlántica patagónica. Revista de Arqueología Americana 15:107-185.

GONZÁLEZ DE BONAVERI, M. 2002. Los cazadores-recolectores-pescadores de la cuenca inferior del Río Salado (Región Pampeana). Tesis Doctoral inédita. Facultad de Filosofía y Letras, Universidad Nacional de Buenos Aires. MS.

GONZÁLEZ DE BONAVERI, M. I.; MOCCIOLA D. y G. GIACOBONE 2003. Identificación de vértebras de peces durante el Holoceno tardío en la región Pampeana Argentina. En: Presence of the archaeoichthyology in Mexico. Memories of the $12^{\text {th }}$ Conference of the ICAZ Fish Remains Working Group, pp. 35-46. Guadalajara.
GONZÁLEZ DE BONAVERI, M., ZANGRANDO A. y M. LANZA 1999. Ictioarqueología y Procesos de Formación: Estudio del Sitio La Guillerma 5-Provincia de Buenos Aires. En: Libro de Resúmenes del XIII Congreso Nacional de Arqueología Argentina, pp. 355-356. Córdoba.

GONZÁLEZ URIARTE, M.; GONZÁLEZ MARTIN, F.; KRUGER, H.; LAMBERTO, S.; ARBANESI, G. y V. DE VERCESI 1987. Evaluación expeditiva del recurso suelo y uso y cobertura de la tierra en el sur de la Pcia. de Buenos Aires. Informe Técnico N²8, INTA. Ascasubi. Argentina.

GRADIN, C. y A. AGUERRE 1984. A modo de resumen. En: Investigaciones arqueológicas en el área Casa de Piedra, pp. 135-144. Editado por Gradin, C. Santa Rosa.

HADJUK, A.; ALBORNOZ, A. y M. J. LEZCANO 2004. El "Mylodon" en el patio de atrás. Informe preliminar sobre los trabajos en el sitio El Trébol, ejido urbano de San Carlos de Bariloche, Provincia de Río Negro. En: Contra Viento y Marea. Arqueología de Patagonia, pp. 715-731. Editado por Civalero, M. T.; Fernández, P. M. y A. G. Guráieb. Buenos Aires.

HOFFMAN, B.; CZEDERPILTZ, J. y M. PARTLOW 2000. Heads or Tails: The Zooarchaeology of Aleut Salmon Storage on Unimak Island, Alaska. Journal of Archaeological Science 27: 699-708.

IZETA, A. 1999. Los ictiorestos arqueológicos del sitio Moreno (costa norte de la provincia de Santa Cruz, República Argentina). En: Actas del XII Congreso Nacional de Arqueología Argentina, pp. 489-492. La Plata.

LISTA, R. 1894. Los indios tehuelches. Una raza que desaparece. Estudio etnológico sobre los tehuelches, según observaciones propias. Buenos Aires.

LUBINSKI, P. 1996. Fish heads, fish heads: an experiment on differential bone preservation in a salmonid fish. Journal of Archaeological Science 23: 175-181.

LYMAN, R. L. 1994.Vertebrate Taphonomy. University Press, Cambridge.

MAC DONAGH, E. J. 1950. Las Razas de Percas o Truchas Criollas (Percichthys) y su Valor para la Repoblación Pesquera. Revista del Museo de la Plata (Nueva Serie) Tomo VI, Sección Zoología: 71-170.

MALAINEY, M.; PRZYBYLSKI, R. y B. SHERRIFF 2001. One person's food: how and why fish avoidance may affect the settlement and subsistence patterns of hunter-gatherers, American Antiquity 66 (1): 141-161.

MARTÍNEZ, G. 2002. Cronología y análisis isotópicos de los entierros humanos del sitio La Petrona (Pdo. de Villarino, Pcia. de Buenos Aires).En: Libro de Resúmenes del III Congreso de Arqueología de la Región Pampeana Argentina, p. 25. Facultad de Ciencias Sociales, UNICEN. Olavarría.

MARTÍNEZ, G. 2004. Resultados Preliminares de las investigaciones arqueológicas realizadas en el curso inferior del río Colorado (Pdos. de Villarino y Patagones). En: Aproximaciones Contemporáneas a la Arqueología Pampeana, pp. 275-292. Editado por Martínez, G.; Gutierrez, M.; Curtoni, R.; Berón, M. y P. Madrid. Publicación de la Facultad de Ciencias Sociales. UNCPBA. Olavarría.

MARTÍNEZ, G y M. J. FIGUERERO TORRES 2000. Sitio arqueológico La Petrona (Pdo. de Villarino, Pcia. de Bs. 
As.): Análisis de las modalidades de entierro en el área Sur pampeana. Relaciones de la Sociedad Argentina de Antropología Tomo XXV: 227-247. Buenos Aires.

MARTÍNEZ, G. y M. GUTIÉRREZ 2004. Tendencias en la explotación humana de la fauna durante el Pleistoceno final-Holoceno en la Región Pampeana (Argentina). En: Zooarchaeology of South America, BAR International Series 1298, pp. 81-98. Editado por Guillermo L. Mengoni Goñalons. Oxford.

MARTÍNEZ, G. y A. F. ZANGRANDO 2004. Análisis de Isótopos Estables y Paleodietas Prehistóricas. Apéndice 7, Informe de período 2003-2004 entregado a Fundación Antorchas. Proyecto "Investigaciones arqueológicas en el valle inferior del Río Colorado-Provincia de Buenos Aires, Argentina". MS.

MARTÍNEZ, G.; FLENSBORG, G.; LÓPEZ, R.; BONETTI, A.; STOESSEL, L. y M. C. ALVAREZ 2004a. Análisis preliminar de los entierros humanos del sitio Paso Alsina 1 (Pdo. de Patagones, Pcia. de Buenos Aires). En: Libro de resúmenes del XV Congreso Nacional de Arqueología Argentina, p. 220. Río Cuarto.

MARTÍNEZ, G.; ARMENTANO, G. y L. STOESSEL 2004b Estratigrafía, cronología, análisis de artefactos líticos y estructura faunística del sitio arqueológico El Tigre (Pdo. de Patagones, Pcia. de Buenos Aires). En: Libro de Resúmenes del XV Congreso Nacional de Arqueología Argentina, p. 353. Río Cuarto.

MARTÍNEZ, G.; LANDINI, C.; STOESSEL, L. y A. BONETTI. 2004c. Estratigrafía, cronología, análisis de artefactos líticos, cerámicos y de restos faunísticos del sitio arqueológico Loma Ruiz 1 (Pdo. de Villarino, Pcia. de Buenos Aires). En: Libro de Resúmenes del XV Congreso Nacional de Arqueología Argentina, p. 354. Río Cuarto.

MELO, W.; SCHILLIZZI, R.; PERILLO G. y M. PICCOLO 2004. Infuencia del área continental pampeana en la evolución morfológica del estuario de Bahía Blanca. Revista de la Sociedad Argentina de Sedimentología 10 (1):39-52.

MENEGAZ, A. 1996. Análisis del material faunístico procedente del sitio Piedra del Águila 11 (Neuquén, Argentina). Praehistoria 2:147-161.

MIOTTI, L. 1993. Ocupación humana de la Patagonia Austral durante el Holoceno. En: El Holoceno en la Argentina (2), pp. 94-130. Editado por Iriondo, M. CADINQUA, La Plata.

MORENO, E. y A. CASTRO 1995. Sitio Moreno: datos preliminares de un sitio chico en la costa norte de Santa Cruz, Argentina. Anales del Instituto de la Patagonia 23: $143-149$

MUSALI, J. 2005. Ictioarqueología del Delta del río Paraná Inferior. El sitio Laguna La Bellaca 2 como caso de estudio. Tesis de Licenciatura Inédita, Universidad de Buenos Aires. MS.

MUSTERS, G. 1997. [1879-70]. Vida entre los Patagones. Editorial Elefante Blanco. Buenos Aires.

NICHOLSON, R. 1992. An assessment of the value of bone density measurements to archaeoichthyological studies. International Journal of Osteoarchaeology 2: 139-154.

ORTUBAY, S. G.; SEMENAS, L. G.; UBEDA, C. A.; QUAGGIOTTO, E. A. y G. P. VIOZZI 1994. Catálogo de
Peces Dulceacuícolas de la Patagonia Argentina y sus Parásitos Metazoos. Dirección de Pesca, Secretaría de Recursos Naturales, Provincia de Río Negro.

OUTES, F. 1926. Noticias sobre el resultado de mis investigaciones antropológicas en la extremidad sudeste de la Provincia de Buenos Aires. Physis 8: 387-390.

PARUELO, J.; JOBBÁGY, E.; SALA, O.; LAUENROTH, W. y I. BURKE 1998. Functional and structural convergence of temperate grassland and shrubland ecosystems. Ecological Applications 8 (1): 194-206.

PALEO, M. C.; PAEZ, M. M. y M. PÉREZ MERONI 2002. Condiciones Ambientales y Ocupación Humana Durante el Holoceno Tardío en el Litoral Fluvial Bonaerense. En: Del Mar a los Salitrales. Diez mil Años de Historia Pampeana en el Umbral del Tercer Milenio, pp. 365 376. Editado por Mazzanti, D.; M. A. Berón y F. W. Oliva. Mar del Plata.

POLITIS, G. y G. MARTÍNEZ 1996. La cacería, el procesamiento de las presas y los tabúes alimenticios. En: Nukak, pp. 231-280. Editado por Politis, G., Instituto Amazónico de Investigaciones Científicas Sinchi. Santafé de Bogota.

POLITIS, G. y SALEMME M. 1990. Pre-hispanic mammal exploitation and hunting strategies in the eastern Pampa subregion of Argentina. En: Hunters of the Recent Past, One World Archaeology 15, pp. 353-372. Editado por Davis, L. y Reeves B. Unwin Hyman. Londres.

POLITIS, G. y N. SAUNDERS 2002. Archaeological Correlates of Ideological Activity: Food Taboos and Spirit-animals in an Amazonian Hunter-gatherer Society. En: Consuming passions and patterns of consumption, pp. 113-130. Editado por Miracle, P. y N. Milber. McDonald Institute Monographs. Cambridge.

PRATES, L. 2004. Arqueología de la cuenca media del Río Colorado (Provincia de Río Negro). Una primera aproximación. Intersecciones en Antropología 5: 55-69.

PRATES, L.; MARTÍNEZ, G. y C. SCABUZZO 2005. Evidencias arqueológicas del Holoceno Tardío final en el curso inferior del Colorado (Pcia. de Río Negro): sitio Don Aldo 1. Bajo consideración. MS.

RICK, T. y J. ERLANDSON 2002. Evaluating the Economic Significance of Sharks, Skates, and Rays (Elasmobranchs) in Prehistoric Economies. Journal of Archaeological Science 29: 111-122.

RINGUELET R. A. 1975. Zoogeografía y ecología de los peces de aguas continentales de la Argentina y consideraciones sobre las áreas icitológicas de America del Sur. Ecosur 2 (3): 1-122.

RINGUELET R. A.; ARAMBURU, R. H. y A. ALONSO DE ARAMBURU 1967. Los peces argentinos de agua dulce. La Plata.

ROSS, E. B. 1978. Food Taboos, Diet and Hunting Strategy: The Adaptation to Animals in Amazon Cultural Ecology. Current Anthropology 19 (1):1-36.

SÁNCHEZ, R.; N. PEZZOLA y J. CEPEDA. 1998. Caracterización edafoclimática del área de influencia del INTA. Boletín de Divulgación 18, INTA. EEA Hilario Ascasubi. Argentina

SCHÄBITZ, F. 1994. Holocene climatic variations in northern Patagonia, Argentina. Palaeogeography, paleoclimatology, palaeoecology 109: 287-294. 
SILVEIRA, M. 1996. Alero los Cipreses (Provincia del Neuquen, República Argentina). En: Arqueología. Solo Patagonia, pp. 107-118. Editado por Gómez Otero, J.. Puerto Madryn.

STEWART, K. y D. GIFFORD-GONZALEZ 1994. An Ethnoarchaeological contribution to identifying hominid fish processing sites. Journal of Archaeological Science 21: $237-248$

VIEDMA, A. (1783) 1972. Descripción de la costa Meridional del Sur llamada vulgarmente Patagonia. En: Colección de Obras y documentos relativos a la historia Antigua y moderna de las Provincias del río de La Plata, Tomo VIII (B), pp. 845-966. Editado por Pedro de Angelis, Editorial Plus Ultra.

VILLAMIL, C. B. y R. L. SCOFFIELD 2003. Evaluación prelimimar de la diversidad vegetal en el partido de Villarino (provincia de Buenos Aires). En: Actas de las II Jornadas Interdisciplinarias del Sudoeste Bonaerense 3, pp. 209-219. Universidad Nacional del Sur. Bahía Blanca.

WEILER, N. 1994 Cambios relativos del nivel marino ocurridos durante el Pleistoceno Tardío-Holoceno en latitudes medias de la República Argentina. En Jornadas de Arqueología e Interdisciplinas, pp. 143-176. Consejo Nacional de Investigaciones Científicas y Técnicas. Programa de Estudios Prehistóricos. Buenos Aires.

ZANGRANDO, A. 2003. Ictioarqueología del Canal Beagle. Explotación de peces y su implicación en la subsistencia humana. Sociedad Argentina de Antropología (Colección Tesis de Licenciatura). Buenos Aires. 